\title{
Water-soluble ZnSe/ZnS:Mn/ZnS quantum dots convert UV to visible light for improved Si solar cell efficiency
}

Hisaaki Nishimura, Takaya Maekawa, Kazushi Enomoto, Naoteru Shigekawa, Tomomi Takagi, Susumu Sobue, Shoichi Kawaic, DaeGwi Kim

\begin{tabular}{|c|l|}
\hline Citation & Journal of Materials Chemistry C. 9(2); 693-701. \\
\hline Issue Date & 2021-01-14 \\
\hline Type & Journal Article \\
\hline Textversion & Author \\
\hline Rights & $\begin{array}{l}\text { The following article has been accepted by Journal of Materials Chemistry C. } \\
\text { This is the accepted manuscript version. } \\
\text { The final, published version is available at https://doi.org/10.1039/D0TC04580B. } \\
\text { Please cite only the published version. }\end{array}$ \\
\hline Supplementary files & Supplementary information is available on https://doi.org/10.1039/D0TC04580B. \\
\hline DOI & 10.1039/D0TC04580B \\
\hline
\end{tabular}

\author{
Self-Archiving by Author(s) \\ Placed on: Osaka City University Repository
}

Nishimura, H., Maekawa, T., Enomoto, K., Shigekawa, N., Takagi, T., Sobue, S., Kawai, S., \& Kim, D. (2021). Water-soluble ZnSe/ZnS:Mn/ZnS quantum dots convert UV to visible light for improved Si solar cell efficiency. Journal of Materials Chemistry C, 9(2), 693-701.

https://doi.org/10.1039/d0tc04580b 


\title{
Water-soluble ZnSe/ZnS:Mn/ZnS quantum dots convert UV to visible light for improved
}

\author{
Si solar cell efficiency
}

Received 00th January 20xx, Accepted 00th January 20xx

DOI: $10.1039 / x 0 \times x 00000 x$

\author{
Hisaaki Nishimuraa , Takaya Maekawa ${ }^{a}$, Kazushi Enomoto ${ }^{b}$, Naoteru Shigekawa $^{a}$, Tomomi Takagic, $^{\mathrm{c}}$ \\ Susumu Sobuec, Shoichi Kawaic, and DaeGwi Kim*a
}

The sensitivity of Si solar cells to the UV portion of the solar spectrum is low, and must be increased to further improve their efficiencies. In this study, water-soluble ZnSe/ZnS:Mn/ZnS core/shell/shell quantum dots (QDs) capable of converting UV into visible light were synthesised by a hydrothermal method. A photoluminescence quantum yield of $84 \%$ was achieved by carefully investigating and optimising the QD preparation conditions. Furthermore, we prepared wavelength-conversion glass containing the ZnSe/ZnS:Mn/ZnS QDs dispersed in sol-gel glass and applied it to Si solar cells. As a result, the spectral sensitivity of the Si solar cell at wavelengths shorter than $400 \mathrm{~nm}$ was significantly improved, and the amount of power generated (conversion efficiency) was increased by $7.4 \%$ compared with that of the cell without the wavelength-conversion glass coating.

\section{Introduction}

Silicon solar cells, as the current most popular solar cell type, account for approximately $90 \%$ of the total solar cell market share. ${ }^{1}$ Some crystalline Si solar cells with conversion efficiencies close to $25 \%$ have been developed. ${ }^{2-4}$ Although $\mathrm{Si}$ solar cells have a high spectral sensitivity towards visible through near-infrared wavelengths of the solar spectrum, their spectral sensitivity to UV light, approximately $10 \%$ of sunlight, is low. The energy conversion efficiency of Si solar cells can be further improved by addressing this issue, for which using phosphor-based wavelength-conversion films has become an effective approach. ${ }^{5-7}$ Thus far, down-shifting UV to visible light and up-shifting infrared to visible light have been extensively investigated for wavelength conversion. ${ }^{7-22}$ However, it is difficult to achieve strong up-conversion luminescence due to the low optical excitation density of sunlight. 21,22 Therefore, down-shifting wavelengthconversion materials are favourable, for which organic dyes, ${ }^{8-10}$ rareearth complexes, ${ }^{11-16}$ and semiconductor quantum dots (QDs) $)^{17-20}$ have been studied as potential phosphors.

Klampaftis et al. improved the conversion efficiency of polycrystalline Si solar cells from $15.07 \%$ to $15.35 \%$ using an EVA polymer containing an organic dye with an emission peak at $413 \mathrm{~nm}$ as a wavelength-conversion material. ${ }^{8}$ Iso et al. fabricated wavelength-conversion films containing rare-earth complexes $\left(\mathrm{YVO} 4: \mathrm{Bi}^{3+}, \mathrm{Eu}^{3+}\right)$ with a photoluminescence quantum yield (PLQY) of

\footnotetext{
a. Department of Applied Physics, Osaka City University, Osaka 558-8585, Japan E-mail: tegi@a-phys.eng.osaka-cu.ac.jp

b. RIKEN Center for Emergent Matter Science (CEMS), Saitama 351-0198, Japan

c. Advanced Research and Innovation Center, DENSO CORPORATION, 500-1

Minamiyama, Komenoki-cho, Nisshin, Aichi 470-0111, Japan

†Electronic supplementary information (ESI) available.
}

$21.4 \%$ and combined them with Si solar cells. ${ }^{11}$ As a result, under UV and near-infrared irradiation, the energy conversion efficiency of the solar cell was increased by $3.19 \%$ as compared to that of the sample without phosphor. However, under AM1.5G simulated solar irradiation, the energy conversion efficiency was reduced because the reflectance in the visible region was increased by the wavelength-conversion film. Beak et al. succeeded in increasing the conversion efficiency of p-type Si solar cells from $16.92 \%$ to $18.00 \%$ using a wavelength-conversion film spin-coated on Si nitride with $\mathrm{Cd}_{0.5} \mathrm{Zn}_{0.5} \mathrm{~S} / \mathrm{ZnS}$ QDs to achieve a PLQY of $80 \% .{ }^{17}$ Wang et al. reported that $\mathrm{Mn}$-doped $\mathrm{CsPbCl}_{3} \mathrm{QDs}$, with a large Stokes shift of over $1 \mathrm{eV}$ and quantum yield of $62 \%$, were coated on multi-crystalline Si solar cells, leading to an increased conversion efficiency of $6.2 \% .{ }^{18}$ They also reported that control of the surface structures was an important factor in improving the solar cell characteristics. ${ }^{23}$

Wavelength-conversion materials for solar cells must possess not only a high PLQY but also suitable anti-photobleaching properties. ${ }^{24}$ Generally, although organic dyes and rare-earth complexes have high PLQYs, their anti-photobleaching properties are lower than those of semiconductor QDs based on inorganic materials. ${ }^{25,26}$ Meanwhile, semiconductor QDs are inferior to organic dyes in terms of PLQY; however, such QDs could have significant potential as wavelengthconversion materials if their PLQY were to be improved because of their favourable anti-photobleaching properties. ${ }^{25} \mathrm{CdSe}$ QDs, which have a narrow size distribution and extremely high PLQY, have been actively studied as a model material to synthesise semiconductor QDs and investigate their optical properties. ${ }^{27}$ However, since the band-edge photoluminescence (PL) comprises most of the PL band, the $\mathrm{PL}$ and absorption spectra overlap. Therefore, re-absorption becomes a problem in applying CdSe QDs as wavelength-conversion materials. Furthermore, CdSe QDs absorb visible light, which reduces the incident light intensity to the solar cell and decreases the energy conversion efficiency. Therefore, wavelength-conversion materials for Si solar cells must be made of an inorganic material with suitable anti-photobleaching properties, have an absorption edge 
wavelength shorter than $400 \mathrm{~nm}$, have limited absorption-PL spectral overlap, and have a high PLQY. CulnS ${ }_{2}$ and $\mathrm{AgInS}{ }_{2}$ QDs have low absorption-PL overlap, i.e., a large Stokes shift. ${ }^{28}$ However, their absorption onset is in the near-infrared to visible region, where the spectral sensitivity of $\mathrm{Si}$ solar cells is high. Therefore, it is desirable to use materials that absorb only wavelengths shorter than $400 \mathrm{~nm}$ to significantly reduce the spectral sensitivity of Si-type solar cells.

Fabricating semiconductor QDs that absorb only UV light requires semiconductor materials with large bandgap energies. For example, since $\mathrm{ZnSe}$ has a bandgap energy of $2.7 \mathrm{eV}$, the absorption onset wavelength can be adjusted to $400 \mathrm{~nm}$ by preparing ZnSe QDs. However, ZnSe QDs generally exhibit band-edge PL with a small Stokes shift in the blue region, where the spectral sensitivity of $S$ solar cells is low. To address this, it is effective to dope QDs with impurities such as $\mathrm{Mn}^{2+}$ or $\mathrm{Cu}^{2+}$ as emission centres to emit visible light, where the spectral sensitivity of Si solar cells is high.

For example, in semiconductor QDs doped with $\mathrm{Mn}^{2+}$ as emission centres, the $Q D$ excitation energy transfers to $\mathrm{Mn}^{2+}$, resulting in orange emission (Mn-related PL (Mn PL)) due to the intra $3 d$-shell ${ }^{4} \mathrm{~T}_{1}$ $\rightarrow{ }^{6} \mathrm{~A}_{1}$ transition of $\mathrm{Mn}^{2+}$. In other words, $\mathrm{Mn}^{2+}$-doped $\mathrm{ZnSe}$ (ZnSe: $\mathrm{Mn}^{2+}$ ) QDs can convert UV to orange light ( $600 \mathrm{~nm}, \sim 2.1 \mathrm{eV}$ ). Therefore, ZnSe:Mn²+ QDs hold significant potential as wavelengthconversion materials for Si solar cells. ${ }^{29,30}$ Thus far, semiconductor QDs doped with impurities have been extensively investigated for application as new functional materials. ${ }^{31-33} \mathrm{Gan}$ et al. reported the synthesis of ZnSe:Mn QDs with a PLQY of $50 \%$ by a nucleation-doping method. ${ }^{34}$ In recent times, Yang et al. developed a synthesis scheme for $\mathrm{Zn}_{1-x} \mathrm{Mn}_{x}$ Se QDs $(x=0.001-0.5)$ involving a reaction in a 1 octadecene solution at high temperatures. ${ }^{35}$

To apply colloidal QDs to wavelength-conversion materials for $S$ solar cells, they must be dispersed in matrices such as polymer films or glasses. ${ }^{36}$ Glasses are stable and transparent bulk materials, making them suitable for use as wavelength-conversion films. ${ }^{36,37}$ The sol-gel method is a well-known approach for dispersing colloidal QDs in glasses. ${ }^{36-39} \mathrm{Li}$ et al. reported a method for uniformly dispersing CdTe QDs in silica-based sol-gel glasses prepared by the hydrolysis of 3-aminopropyltrimethoxysilane. ${ }^{36}$ To uniformly disperse QDs in a glass, the sol-gel silica and colloidal QDs must be mixed well. Since QDs synthesised by the hot-injection method are hydrophobic, they are difficult to disperse in sol-gel glasses. Thus, water-soluble QDs are desirable. One method to prepare watersoluble QDs involves the ligand-exchange reaction of oil-soluble QDs synthesised by the hot-injection method. ${ }^{40,41}$ Selvaraj et al. prepared water-soluble ZnSe:Mn/ZnS core/shell nanorods with a PLQY of $49 \%$ via the ligand exchange process. ${ }^{42}$ However, this process was known to degrade the PL properties of oil-soluble QDs. ${ }^{40}$ Therefore, the direct synthesis of water-soluble QDs remained important. Aboulaich et al. reported on the synthesis of water-soluble $\mathrm{ZnSe}: \mathrm{Mn}$ and ZnSe:Mn/ZnS core/shell QDs with PLQYs of 3.5\% and 9\%, respectively, using a reflux method. ${ }^{43}$ Hardzei et al. successfully synthesised ZnSe:Mn/ZnS core/shell QDs with PLQYs of $10 \%$ using a hydrothermal method. ${ }^{44}$ However, the PLQYs of these samples are much lower than those of QDs synthesised by the hot-injection method. Therefore, it was necessary to synthesise water-soluble Mn-doped ZnSe QDs with higher PLQYs.

In previous studies on the synthesis of water-soluble $\mathrm{Mn}$-doped ZnSe QDs, most samples emitted weak Mn PL. Especially, we prepared ZnSe:Mn QDs in a previous work, wherein the core ZnSe QD was directly doped with $\mathrm{Mn}^{2+}$, but their PLQY was only approximately $20 \% .^{29}$ In contrast, hydrothermally synthesised nondoped ZnSe QDs and ZnSe/ZnS QDs exhibit high PLQYs of over $60 \%$ and $90 \%$, respectively. ${ }^{45}$ The major difference between the PLQYs of
ZnSe and ZnSe:Mn QDs is considered the $\mathrm{pH}$ of the precursor solution, which is well known as an essential parameter in the hydrothermal synthesis of semiconductor QDs. ${ }^{46,47}$ The optimum $\mathrm{pH}$ for the synthesis of the ZnSe QDs has been reported as $6 .{ }^{45}$ In contrast, if ZnSe:Mn QDs are synthesised at $\mathrm{pH}$ 6, no $\mathrm{Mn} \mathrm{PL}$ is observed, i.e., $\mathrm{Mn}^{2+}$ cannot be doped. ${ }^{29}$ The use of an alkaline precursor solution enables $\mathrm{Mn}^{2+}$ doping, wherein a $\mathrm{ZnSe}: \mathrm{Mn}$ precursor at $\mathrm{pH} 10$ yields the highest Mn PL. ${ }^{29}$ However, the PLQY of ZnSe QDs synthesised under alkaline conditions is low. ${ }^{46}$ In other words, the condition necessary for $\mathrm{Mn}^{2+}$ doping ( $\mathrm{pH} 10$ ) is significantly different from the optimum condition for preparing the host ZnSe QDs to suppress nonradiative recombination processes $(\mathrm{pH} 6)$. This is the reason for the low PLQYs of ZnSe:Mn QDs. Additionally, it is also difficult to dope QDs with impurities like $\mathrm{Mn}^{2+}$ due to self-purification, wherein impurities are removed during QD growth. $32,48,49$ Thus, new strategies are needed to synthesise Mn-doped ZnSe QDs with strong Mn PL. ${ }^{50-52}$ Wood et al. reported the synthesis of oil-soluble $\mathrm{ZnSe} / \mathrm{ZnS}: \mathrm{Mn} / \mathrm{ZnS}$ QDs with a PLQY of $65 \%$ by forming ZnS:Mn innershell and ZnS outer-shell layers on the surface of ZnSe-core QDs using a hot-injection method. ${ }^{50}$ Luong et al. also reported the preparation of water-soluble $\mathrm{ZnSe} / \mathrm{ZnS}: \mathrm{Mn} / \mathrm{ZnS}$ core/shell/shell QDs by a reflux method, but their PLQY remained low at $42.9 \% .^{52}$

In this study, we focused on the $\mathrm{Mn}^{2+}$ doping of the shell layer instead of directly doping the core QDs of the ZnSe host (Figure 1a). To apply water-soluble ZnSe/ZnS:Mn/ZnS core/shell/shell QDs as wavelength-conversion materials and improve the conversion efficiency of Si solar cells, the PLQY must be maximised. Therefore, we investigated the preparation conditions of the $\mathrm{ZnSe} / \mathrm{ZnS}: \mathrm{Mn} / \mathrm{ZnS}$ QDs using $N$-acetyl-L-cysteine (NAC)-capped ZnSe QDs, which have the highest PLQY among aqueous ZnSe QDs reported thus far, as the core QDs, and finally succeeded in increasing the PLQY to $84 \%$. The prepared QDs were then dispersed in a sol-gel glass to fabricate highly luminescent wavelength-conversion glass with a transmissivity over $90 \%$ in the visible region (Figure 1b). The conversion efficiency of the $\mathrm{Si}$ solar cells with the wavelengthconversion glass was improved by $7.4 \%$ (Figure $1 c$, d), which is the highest conversion efficiency improvement yet achieved for Si solar cells using wavelength-conversion materials.

\section{Experimental Section}

\section{Preparation of $\mathrm{ZnSe}$ precursor solution}

The ZnSe precursor solution was prepared by the method reported by Lee et al.. ${ }^{45}$ Briefly, $\mathrm{Zn}\left(\mathrm{ClO}_{4}\right)_{2} \cdot 6 \mathrm{H}_{2} \mathrm{O}(1.0 \mathrm{mmol})$ and $\mathrm{N}$-acetyl-Lcysteine (NAC) $(2.4 \mathrm{mmol}$ ) as a ligand were dissolved in $50 \mathrm{~mL}$ of deionised (DI) water. The $\mathrm{pH}$ of the solution was adjusted to 8.5 , and a freshly prepared solution of NaHSe $(0.2 \mathrm{mmol})$ was added. Then, the $\mathrm{pH}$ was adjusted to 6.0 by adding diluted $\mathrm{HCl}$.

\section{Preparation of $\mathrm{ZnS}: \mathrm{Mn}$ precursor solution}

The ZnS:Mn precursor solution was prepared by adding a $\mathrm{Mn}^{2+}$ source to the $\mathrm{ZnS}$ precursor solution. $\mathrm{Zn}\left(\mathrm{ClO}_{4}\right)_{2} \cdot 6 \mathrm{H}_{2} \mathrm{O}(1.2 \mathrm{mmol})$ and NAC ( $8.4 \mathrm{mmol}$ ) were dissolved in $20 \mathrm{~mL}$ of DI water. Subsequently, $\mathrm{NaOH}$ was added to adjust the $\mathrm{pH}$ to 4.0 , and $\mathrm{Na}_{2} \mathrm{~S} \cdot 9 \mathrm{H}_{2} \mathrm{O}(0.24 \mathrm{mmol})$ and $\mathrm{Mn}\left(\mathrm{ClO}_{4}\right)_{2} \cdot 6 \mathrm{H}_{2} \mathrm{O}(0.15 \mathrm{mmol})$ were added. To determine the optimum conditions, we prepared $\mathrm{ZnS}: \mathrm{Mn}$ precursor solutions with different molar ratios of $\mathrm{Zn}^{2+}, \mathrm{NAC}$, and $\mathrm{Mn}^{2+}$.

\section{Preparation of $\mathrm{ZnS}$ precursor solution}


The ZnS precursor solution was prepared as follows. First, NAC (7.2 $\mathrm{mmol}$ ) was dissolved in $50 \mathrm{~mL}$ of DI water, then $\mathrm{Zn}\left(\mathrm{ClO}_{4}\right)_{2} \cdot 6 \mathrm{H}_{2} \mathrm{O}(3.0$ mmol) was added as a $\mathrm{Zn}^{2+}$ source. Subsequently, $\mathrm{NaOH}$ was added to this solution to adjust the $\mathrm{pH}$ to 4.0 , and $\mathrm{Na}_{2} \mathrm{~S} \cdot 9 \mathrm{H}_{2} \mathrm{O}(0.6 \mathrm{mmol})$ was added. The $\mathrm{pH}$ of the $\mathrm{ZnS}$ precursor solution was then adjusted to different values to determine the optimal conditions.

\section{Synthesis of ZnSe/ZnS:Mn/ZnS core/shell/shell QDs}

Firstly, ZnSe core QDs were prepared by the hydrothermal method reported by Lee et al.. ${ }^{45,46}$ The $\mathrm{ZnSe}$ precursor solution $(10 \mathrm{~mL})$ was loaded into an autoclave and incubated at $200{ }^{\circ} \mathrm{C}$ for $60 \mathrm{~min}$. The PLQY of the ZnSe-core QDs was $60 \% .{ }^{46}$ To synthesise the ZnSe/ZnS:Mn/ZnS core/shell/shell QDs, ZnS:Mn and ZnS shells were prepared by microwave-assisted hydrothermal synthesis. ${ }^{46}$ The $\mathrm{ZnS}: \mathrm{Mn}$ precursor solution was then added to the prepared $\mathrm{ZnSe}$ core QD solution, and ZnSe/ZnS:Mn core/shell QDs were synthesised by microwave irradiation for $2 \mathrm{~min}$ at $120^{\circ} \mathrm{C}$ using a single-mode CEM Discover system. To determine the optimal amount of $\mathrm{ZnS}: \mathrm{Mn}$ precursor, the ZnSe core QD solution and ZnS:Mn precursor solution were mixed at different ratios. Finally, the $Z n S$ precursor was added to the ZnSe/ZnS:Mn core/shell QD solution, and ZnSe/ZnS:Mn/ZnS core/shell/shell QDs were synthesised under microwave irradiation at $140{ }^{\circ} \mathrm{C}$. The $\mathrm{ZnS}$ precursor was added gradually in five steps and heated to fix the total amount of added $\mathrm{ZnS}: \mathrm{Mn}$ and $\mathrm{ZnS}$ precursors. The heating time was gradually increased to $4,4,6,6$, and $10 \mathrm{~min}$.

\section{Preparation of wavelength-conversion glass}

The wavelength-conversion glass was prepared by dispersing the ZnSe/ZnS:Mn/ZnS QDs in sol-gel glass according to a previously reported method. ${ }^{37} \mathrm{~A}$ mixed solution of $11 \mathrm{mM}$ aqueous citric acid (2 $\mathrm{mL}$ ) and 3-aminopropyltrimethoxysilane $(2 \mathrm{~mL})$ was stirred in a Teflon chalet $(\varphi=34 \mathrm{~mm})$ for $24 \mathrm{~h}$ to promote hydrolysis. To concentrate the QD solution, the ZnSe/ZnS:Mn/ZnS QDs were precipitated by adding 2-propanol to the $\mathrm{QD}$ solution, and the solution was centrifuged at 3,500 rpm for $20 \mathrm{~min}$. The precipitates were then re-dispersed with $\mathrm{DI}$ water to increase the concentration by 10 times. Subsequently, $1 \mathrm{~mL}$ of an aqueous solution containing the $\mathrm{ZnSe} / \mathrm{ZnS}: \mathrm{Mn} / \mathrm{ZnS}$ QDs and $0.3 \mathrm{~mL}$ of an additional $\mathrm{Zn}^{2+}$ solution $\left(0.48 \mathrm{mmol}\right.$ of $\mathrm{Zn}\left(\mathrm{ClO}_{4}\right)_{2} \cdot 6 \mathrm{H}_{2} \mathrm{O}$ and $2.40 \mathrm{mmol}$ of NAC mixed in $10 \mathrm{~mL}$ of $\mathrm{DI}$ water) was added to the sol-gel solution. The obtained samples were applied to the Si solar cells and dried in the dark. The thickness of the wavelength-conversion glass was $200 \mu \mathrm{m}$.

\section{Chemicals}

For the experiment, $\mathrm{Zn}\left(\mathrm{ClO}_{4}\right)_{2} \cdot 6 \mathrm{H}_{2} \mathrm{O}$ and $\mathrm{Mn}\left(\mathrm{ClO}_{4}\right)_{2} \cdot 6 \mathrm{H}_{2} \mathrm{O}$ were purchased from Fujifilm Wako Chemicals, and selenium (99.999\%) was purchased from Aldrich. Furthermore, $\mathrm{Na}_{2} \mathrm{~S} \cdot 9 \mathrm{H}_{2} \mathrm{O}$ was purchased from Kisida Chemical, and 3-aminopropyltrimethoxysilane was purchased from Tokyo Kasei.

\section{Characterisation and spectroscopic measurements}

The absorption spectra were obtained using a JASCO V-650 UV-Vis spectrophotometer with a spectral resolution of $0.5 \mathrm{~nm}$. The PL spectra were measured with a JASCO FP-8300 spectrofluorometer at an excitation wavelength of $325 \mathrm{~nm}$ and spectral resolution of $0.5 \mathrm{~nm}$, and the PL intensity of each sample was determined by dividing the PL intensity by the absorption intensity at the excitation wavelength. The absolute PLQY was measured using a JASCO ILF-835 100 mm integrating sphere system coupled with the spectrofluorometer. To measure the PL decay profiles, the third-harmonic-generated light (355 nm) from a laser-diode-pumped yttrium aluminium garnet laser with a pulse duration of $20 \mathrm{~ns}$ and repetition rate of $20 \mathrm{~Hz}$ was used as the excitation source. The PL decay profiles were observed by a $500 \mathrm{MHz}$ digitising oscilloscope. High-resolution electron microscopy images were obtained using a JEOL JEM-2100F/SP. Energy-dispersive $X$-ray spectroscopy (EDX) was also performed to estimate the actual doping amount of $\mathrm{Mn}^{2+}$. Field emission scanning electron microscopy (FE-SEM) image was obtained using a JEOL JSM-6500F.

\section{Evaluation of solar cell characteristics}

The Si solar cell modules (10 mm $\times 10 \mathrm{~mm}, \eta=20.0 \pm 1.1 \%)$ were fabricated by K-I-S (Japan). The solar cell module with wavelengthconversion glass was fabricated by dropping the sol-gel solution onto the cell, then drying in a flat, dark location. The droplet volume of the sol-gel solution was adjusted such that the film thickness after drying was $200 \mu \mathrm{m}$. The $I-V$ curves (Wacom electric, WXS-156S-10, AM1.5 G $100 \mathrm{~mW} / \mathrm{cm}^{2}$ ) and EQE (Bunkoukeiki, SM-250CE, $1.0 \mathrm{~mW} / \mathrm{cm}^{2}$ ) were estimated using a solar simulator. The surface reflectance of the Si solar cell modules was determined using a QE-R3011 (Enli Technology Co., Ltd.).

\section{Results and discussion}

Figure S1 shows the absorption and PL spectra of the ZnSe:Mn/ZnS core/shell QDs prepared from a pH $10 \mathrm{ZnSe:Mn} \mathrm{precursor} \mathrm{solution.}$ The PL spectrum consists of a PL band originating from the intra-3d shell transition of $\mathrm{Mn}^{2+}$ with a peak near $2.1 \mathrm{eV}$ and band-edge PL. The PLQY of the ZnSe:Mn QDs was $20 \%$, which was increased to $30 \%$ by introducing a $\mathrm{ZnS}$ shell to the surfaces. Although the PLQY was improved by preparing ZnSe:Mn/ZnS core/shell QDs, further increasing the PLQY requires a fundamental improvement in the synthetic method. Here, instead of directly doping $\mathrm{Mn}^{2+}$ into the ZnSe-core QDs, as described above, non-doped ZnSe QDs prepared under optimal conditions were used as host QDs. Then, the ZnS:Mn shell was introduced using an alkaline precursor solution. Finally, to improve the PLQY, a ZnS capping layer was applied to yield multishell ZnSe/ZnS:Mn/ZnS core/shell/shell QDs.

Figure 2 shows the absorption and $\mathrm{PL}$ spectra of the ZnSe/ZnS:Mn/ZnS core/shell/shell QDs synthesised as follows. First, the $\mathrm{ZnS}: \mathrm{Mn}$ precursor solution was prepared with a $\mathrm{Zn}^{2+}: \mathrm{S}^{2-}: \mathrm{NAC}: \mathrm{Mn}^{2+}$ molar ratio of 1.0:0.2:4.8:0.1 at $\mathrm{pH}$ 10.5. Then, the $\mathrm{ZnSe-core} \mathrm{QD} \mathrm{solution} \mathrm{and} \mathrm{ZnS:Mn} \mathrm{precursor} \mathrm{solution} \mathrm{were} \mathrm{mixed} \mathrm{at}$ a ratio of $[\mathrm{ZnS}: \mathrm{Mn}] /[\mathrm{ZnSe}]=1.0$ based on the molar ratio of $\mathrm{Zn}^{2+}$ in each solution. The mixed solution was heated by microwave irradiation to prepare $\mathrm{ZnSe} / \mathrm{ZnS}: \mathrm{Mn}$ core/shell QDs. Subsequently, ZnSe/ZnS:Mn/ZnS core/shell/shell QDs were prepared by adding a ZnS outer shell precursor solution and heating by microwave irradiation. As shown in Figure 2, these QDs have a stronger Mn PL than the ZnSe:Mn/ZnS QDs. In other words, this method is effective for synthesising Mn-doped ZnSe QDs. In the ZnSe/ZnS:Mn/ZnS 
core/shell/shell QDs, however, band-edge PL was also clearly observed because of the presence of many non-doped ZnSe/ZnS QDs. Therefore, we attempted to optimise each synthesis step according to the following four conditions: the amount of added $\mathrm{ZnS}: \mathrm{Mn}$ precursor, the $\mathrm{pH}$ of the $\mathrm{ZnS}$ outer shell precursor, the molar ratio of $[\mathrm{NAC}] /[\mathrm{Zn}]$ in the $\mathrm{ZnS}: \mathrm{Mn}$ precursor, and the concentration of $\mathrm{Mn}^{2+}$ in the $\mathrm{ZnS}: \mathrm{Mn}$ precursor. Figure S2 shows the flowchart of the optimisation experiments. The integrated Mn PL intensities for each condition are plotted in Figure $3 a-d$, and the PL spectra are shown in Figure S3. The excitation wavelength was fixed at $325 \mathrm{~nm}$. The PL intensity of each sample was compared by dividing the PL intensity by the absorption intensity at the excitation wavelength. Therefore, the relative PLQY of each sample can be compared.

First, we investigated the dependence of the Mn PL intensity on the mixing ratio of the $\mathrm{ZnSe}$-core QD solution and $\mathrm{ZnS}: \mathrm{Mn}$ precursor solution, which was defined by the molar ratio of $\mathrm{Zn}$ ions contained in each one ([ZnS:Mn]/[ZnSe]). Here, the Mn concentration, defined as the molar ratio of $\mathrm{Zn}$ and $\mathrm{Mn}$ ions in the $\mathrm{ZnS}: \mathrm{Mn}$ precursor solution, was fixed at $10 \%$. The $\mathrm{pH}$ of the $\mathrm{ZnS}$ outer shell precursor was fixed at 6.0. Figure $3 a$ shows the integrated $\mathrm{Mn} \mathrm{PL}$ intensity for $[\mathrm{ZnS}: \mathrm{Mn}] /[\mathrm{ZnSe}]=1.0,1.5,2.0,2.5$, and 3.0, showing that the maximum was obtained for [ZnS:Mn]/[ZnSe] $=2.0$.

Next, the dependence of the Mn PL intensity on the $\mathrm{pH}$ of the $\mathrm{ZnS}$ outer shell precursor was investigated. ZnSe/ZnS:Mn/ZnS core/shell/shell QDs were synthesised using ZnS precursors at $\mathrm{pH} 3.5$, 4.0, 4.3, 4.5, 4.8, 5.5, 6.0, and 6.5. The $[\mathrm{ZnS}: \mathrm{Mn}] /[\mathrm{ZnSe}]$ ratio was fixed to 2.0. As shown in Figure $3 \mathrm{~b}$, the optimal $\mathrm{ZnS}$ precursor $\mathrm{pH}$ was found to be 4.5 .

To determine the optimum [NAC]/[Zn] molar ratio in the ZnS:Mn precursor solution, we synthesised $\mathrm{ZnSe} / \mathrm{ZnS}: \mathrm{Mn} / \mathrm{ZnS}$ core/shell/shell QDs at $[\mathrm{NAC}] /[\mathrm{Zn}]=2.4-9.6$. As shown in Figure S3c, band-edge $\mathrm{PL}$ was recognised to be dominant under the condition of $[\mathrm{NAC}] /[\mathrm{Zn}]=2.4$. It is well known that ligands play a major role in QD synthesis. Therefore, in this study, we also investigated the $[\mathrm{NAC}] /[\mathrm{Zn}]$ molar ratio in detail. It was considered that the band-edge $\mathrm{PL}$ became strong because the escape of $\mathrm{Mn}$ from the QDs due to the self-purification effect could not be suppressed when $[\mathrm{NAC}] /[\mathrm{Zn}]=$ 2.4. When $[\mathrm{NAC}] /[\mathrm{Zn}]>4.8$, the band-edge-PL intensity decreased, and $\mathrm{Mn} \mathrm{PL}$ became dominant. Figure $3 \mathrm{c}$ shows the $\mathrm{Mn} \mathrm{PL}$ intensity as a function of $[\mathrm{NAC}] /[\mathrm{Zn}]$, illustrating that the maximum was observed at $[N A C] /[Z n]=7.2$.

Finally, we investigated the dependence of the Mn PL intensity on the $\mathrm{Mn}$ concentration of the $\mathrm{ZnS}: \mathrm{Mn}$ shell precursor. Figure $3 \mathrm{~d}$ shows the Mn-PL intensity of the ZnSe/ZnS:Mn/ZnS core/shell/shell QDs prepared at $\mathrm{Mn}$ concentrations between $1 \%$ and $20 \%$, illustrating that the maximum was observed at $15 \%$.

From the above, the optimum conditions for the synthesis of ZnSe/ZnS:Mn/ZnS core/shell/shell QDs were determined as follows. (1) First, non-doped ZnSe QDs were synthesised as hosts. (2) The ZnS:Mn shell precursor was prepared at $\mathrm{Zn}: \mathrm{S}: N A C: M n=1 \cdot 0: 0.2: 7.2: 0.15$ and adjusted $\mathrm{pH}$ 10.5. (3) Then, the $\mathrm{ZnS}: \mathrm{Mn}$ precursor was mixed with the previously prepared ZnSe-core QD solution at $[\mathrm{ZnS}: \mathrm{Mn}] /[\mathrm{ZnSe}]=2.0$, and $\mathrm{ZnSe} / \mathrm{ZnS}: \mathrm{Mn}$ core/shell QDs were synthesised by microwave irradiation at $120^{\circ} \mathrm{C}$ for $2 \mathrm{~min}$. (4) The ZnS precursor was prepared at a Zn:S:NAC molar ratio of 1.0:0.2:2.4 and adjusted to $\mathrm{pH} 4.5$, then added to the solution from step (3) at $[\mathrm{ZnS}] /[\mathrm{ZnSe}]=9$ and heated at $140{ }^{\circ} \mathrm{C}$ for $2 \mathrm{~min}$ by microwave irradiation. (5) Finally, to form the ZnS outer shell, the addition of the $\mathrm{ZnS}$ precursor and subsequent heating were repeated 5 times. The optimum conditions for the total amount of added [ZnS] were $([\mathrm{ZnS}: \mathrm{Mn}]+[\mathrm{ZnS}]) /[\mathrm{ZnSe}]=61$.

The absorption and PL spectra of the $\mathrm{ZnSe} / \mathrm{ZnS}: \mathrm{Mn} / \mathrm{ZnS}$ core/shell/shell QDs prepared under the optimum conditions are shown in Figure $4 a$, illustrating the achieved PLQY of $84 \%$. To the best of our knowledge, this PLQY is the highest reported thus far for water-soluble Mn-doped ZnSe QDs. From the EDX measurements, the $\mathrm{Mn}$ concentration in the $\mathrm{ZnSe} / \mathrm{ZnS}: \mathrm{Mn} / \mathrm{ZnS}$ QDs, synthesized under optimal conditions, was confirmed to be $1 \%$. A typical transmission electron microscope (TEM) image is shown in Figure $4 \mathrm{~b}$, and Figure $4 \mathrm{c}$ shows photographs of the water-soluble ZnSe/ZnS:Mn/ZnS core/shell/shell QDs under a room light and UV excitation. The solution was highly transparent to visible light and showed strong orange emission under UV irradiation. Figure 4d shows the PL decay profile measured at the PL peak of $2.1 \mathrm{eV}$ for the $\mathrm{ZnSe} / \mathrm{ZnS}: \mathrm{Mn} / \mathrm{ZnS}$ QDs. The PL decay profile was fitted using the sum of three single exponential functions $I(t)=\sum A_{i} \cdot \exp \left(-t / \tau_{i}\right)$, and the average lifetime was calculated using $\langle\tau\rangle=\sum A_{i} \tau_{i}^{2} / \sum A_{i} \tau_{i}{ }^{53}$ Here, $A_{i}$ represents the weight of each component. The obtained $\langle\tau\rangle$ was approximately $2.2 \mathrm{~ms}$; this long lifetime of the order of milliseconds was consistent with the intrinsic nature of the intra- $3 d$ transition of the Mn dopant. ${ }^{34,35,53}$

By optimising the preparation conditions, we synthesised ZnSe/ZnS:Mn/ZnS core/shell/shell QDs with a wavelength conversion function and maximised PLQY. To apply the water-soluble ZnSe/ZnS:Mn/ZnS QDs to wavelength-conversion materials and improve the conversion efficiency of Si solar cells, the prepared QDs were dispersed in sol-gel glass to fabricate highly luminescent wavelength-conversion glass (Figure $1 b$ ). The higher the $Q D$ concentration, the better it would be for the application of the $\mathrm{Si}$ solar cells. However, the dispersibility decreased and the $Q D$ aggregated when the QD concentration was too high, causing the $Q D$ glass to become cloudy, leading to remarkably lowered transmittance. Therefore, the QD concentration was increased within the range wherein white turbidity due to aggregation did not occur. The transmission spectrum of the QD glass is shown in Figure S4a. While the transmittance is close to $90 \%$ for visible light $(>400$ $\mathrm{nm})$, the transmittance decreases sharply for UV light $(<400 \mathrm{~nm})$. Additionally, as shown in Figure $54 b$, the QD glass emits strong orange PL. Thus, we succeeded in fabricating optimal wavelength conversion for Si solar cells.

The QD glass was then applied to a commercially available Si solar cell module. To investigate whether the wavelength-conversion function of the QD glass improves the conversion efficiency, we compared the output characteristics of $\mathrm{Si}$ solar cells with and without the QD glass. Figure S5 shows the surface reflectance of the solar cells before and after applying the QD glass. In the wavelength range from $400 \mathrm{~nm}$ to $1200 \mathrm{~nm}$, the reflectance before and after applying the QD glass were the same. In contrast, in the wavelength region below $400 \mathrm{~nm}$, the reflectance increased applying the QD glass. For measuring reflectance, monochromatic light was irradiated onto a sample and the reflected light was detected. Since the reflected light from the sample was directly incident on the photodetector, we considered that $\mathrm{PL}$ from the $\mathrm{QD}$ glass was detected. Figure $\mathrm{S} 6$ shows the SEM image of the solar cell with the QD glass, which confirms 
that a flat surface is formed without cracks or visible irregularities. Furthermore, we considered that the flatness of this QD glass ensured its high transmittance.

Figure 5 a shows the $I-V$ curves of the solar cells. The short-circuit current density $\left(J_{\mathrm{sc}}\right)$ increased from 42.4 to $43.5 \mathrm{~mA} / \mathrm{cm}^{2}$ upon adding the $Q D$ glass. Furthermore, as shown in the external quantum efficiency (EQE) spectra in Figure $5 b$, the solar cell with the QD glass showed a clear increase in EQE in the UV region. Since fluorescent thin films such as the QD glass act as light guide plates, fluorescence is lost from the end face of the glass toward the outside ${ }^{54,55}$, thereby hindering improvements to the solar cell efficiency. Therefore, to further improve the output characteristics of the solar cell by reducing the light loss, Al tape was attached to the side of the solar cell with the QD glass. As shown in Figure $5 \mathrm{a}$, the $J_{\mathrm{sc}}$ increased from 43.5 to $44.4 \mathrm{~mA} / \mathrm{cm}^{2}$ upon the addition of the Al tape, and as shown in Figure $5 b$, the EQE was also increased further. These results demonstrated that the Al tape reduced the loss of light from the end face and improves the power generation efficiency.

As a result, the conversion efficiency of the Si solar cell was improved from $20 \%$ to $20.7 \%$ by adding the QD glass. Furthermore, by suppressing the light loss with the Al tape, the efficiency was improved to $21.5 \%$. Overall, the conversion efficiency of the solar cell with the wavelength-conversion glass and Al tape was improved by 7.4\% compared with that of the bare solar cell. The change in EQE was small, relative to the improvement rate of $J_{s c}$ in the $I-V$ measurements, mainly due to the differences in experimental conditions between the $I-V$ and EQE measurements. The first reason was the difference in the irradiation light area. The solar cell module used in this study had a Si solar cell area of $10 \mathrm{~mm} \times 10 \mathrm{~mm}\left(1.0 \mathrm{~cm}^{2}\right)$ and a protective glass area of $15 \mathrm{~mm} \times 15 \mathrm{~mm}\left(2.25 \mathrm{~cm}^{2}\right)$. The irradiation area in the EQE measurement was $10 \mathrm{~mm} \times 10 \mathrm{~mm}$, and the Si solar cell was irradiated. During the $I-V$ measurement, the entire module, including the protective glass, was irradiated. Since the irradiation area was larger in the $I-V$ measurement, not only the pseudo-sunlight directly incident on the Si solar cell, but also the light emitted from the QD glass outside the solar cell, reaches the Si solar cell. Therefore, the improvement rate of $J_{s c}$ in the $I-V$ measurements increased. Another difference in the experimental conditions between $I-V$ and EQE measurements was the difference in irradiation light intensity. The irradiation light intensities during the EQE and $I-V$ measurements were 1.0 and $100 \mathrm{~mW} / \mathrm{cm}^{2}$, respectively. Since the irradiation light intensity in the $I-V$ measurement was 100 times greater than that in the EQE measurement, the contribution of $\mathrm{PL}$ from the aforementioned QD glass in the EQE measurement was increased further, and consequently, the improvement rate of $J_{\mathrm{sc}}$ was increased. The results of the EQE measurements confirm the effect of wavelength conversion by the ZnSe/ZnS:Mn/ZnS QDs. However, it was considered that the improvement in power generation efficiency was due not only to the wavelength conversion function by the QDs, but also to the increase in effective absorption in the Si solar cell coated with the QD glass and with the Al tape. Therefore, it is suggested that the conversion efficiency may be improved further by optimising the device structure, including the wavelengthconversion glass.

\section{Conclusions}

In conclusion, water-soluble ZnSe/ZnS:Mn/ZnS QDs with a high PLQY of $84 \%$ were synthesised by a hydrothermal method and applied to wavelength-conversion materials to improve the conversion efficiency of Si solar cells. During synthesis of the ZnSe/ZnS:Mn/ZnS QDs, non-doped ZnSe QDs were used as hosts, and we focused on $\mathrm{Mn}^{2+}$ doping of the shell layer instead of directly doping the core QDs. Additionally, the ZnSe/ZnS:Mn/ZnS QDs were dispersed in sol-gel glass to prepare wavelength-conversion glass. By adding this glass to the top of a solar cell, the power generation efficiency increased by $7.4 \%$ (from $20.0 \%$ to $21.5 \%$ ). These results demonstrated that the highly luminescent $\mathrm{Mn}$-doped ZnSe QDs possessed significant potential for application as wavelength-conversion materials.

\section{Conflicts of interest}

There are no conflicts to declare.

\section{Acknowledgements}

N.S. and D.K. acknowledges a Grant-in-Aid for Scientific Research (B) (No. 17H03538) from the Japan Society for the Promotion of Science (KAKENHI). This work was also supported by JST OPERA Program (JPMJOP1843).

\section{References}

1 E. Placzek-Popko, Opto-Electronics Review, 2017, 25, 55-64.

2 M. A. Green, E. D. Dunlop, D. H. Levi, J. Hohl-Ebinger, M. Yoshita and A. W. Y. Ho-Baillie, Progress in Photovoltaics, 2019 27, 565-575.

3 K. Yoshikawa, H. Kawasaki, W. Yoshida, T. Irie, K. Konishi, K. Nakano, T. Uto, D. Adachi, M. Kanematsu, H. Uzu and K. Yamamoto, Nature Energy, 2017, 2, 17032.

4 A. Richter, J. Benick, F. Feldmann, A. Fell, M. Hermle and S. W. Glunz, Solar Energy Materials and Solar Cells, 2017, 173, 96105.

5 B. S. Richards, Solar Energy Materials and Solar Cells, 2006, 90 , 2329-2337.

6 X. Y. Huang, S. Y. Han, W. Huang and X. G. Liu, Chemical Society Reviews, 2013, 42, 173-201.

7 B. McKenna and R. C. Evans, Advanced Materials, 2017, 29, 160649.

8 E. Klampaftis and B. S. Richards, Progress in Photovoltaics, 2011, 19, 345-351

9 L. Danos, T. Parel, T. Markvart, V. Barrioz, W. S. M. Brooks and S. J. C. Irvine, Solar Energy Materials and Solar Cells, 2012, 98, 486-490.

10 A. Solodovnyk, C. Kick, A. Osvet, H. J. Egelhaaf, E. Stern, M. Batentschuk, K. Forberich and C. J. Brabec, Energy Technology, 2016, 4, 385-392.

11 Y. Iso, S. Takeshita and T. Isobe, Journal of the Electrochemical Society, 2012, 159, J72-J76.

12 B. S. Richards, Solar Energy Materials and Solar Cells, 2006, 90, 1189-1207.

13 K. Fujita, R. Watanabe, Y. Iso and T. Isobe, Journal of Luminescence, 2018, 198, 243-250.

14 B. M. van der Ende, L. Aarts and A. Meijerink, Physical Chemistry Chemical Physics, 2009, 11, 11081-11095.

15 G. Griffini, F. Bella, F. Nisic, C. Dragonetti, D. Roberto, M. Levi, R. Bongiovanni and S. Turri, Advanced Energy Materials, 2015, 5, 1401312 . 
16 T. Fukuda, S. Kato, E. Kin, K. Okaniwa, H. Morikawa, Z. Honda and N. Kamata, Optical Materials, 2009, 32, 22-25.

17 S. W. Baek, J. H. Shim and J. G. Park, Physical Chemistry Chemical Physics, 2014, 16, 18205-18210.

18 F. Y. Wang, M. F. Yang, S. H. Ji, L. L. Yang, J. L. Zhao, H. L. Liu, Y. R. Sui, Y. F. Sun, J. H. Yang and X. D. Zhang, Journal of Power Sources, 2018, 395, 85-91.

19 I. Levchuk, C. Wurth, F. Krause, A. Osvet, M. Batentschuk, U. Resch-Genger, C. Kolbeck, P. Herre, H. P. Steinruck, W. Peukert and C. J. Brabec, Energy \& Environmental Science, 2016, 9, 1083-1094.

20 Q. Wang, X. S. Zhang, Z. W. Jin, J. R. Zhang, Z. F. Gao, Y. F. Li and S. Z. F. Liu, ACS Energy Letters, 2017, 2, 1479-1486.

21 A. Shalav, B. S. Richards and M. A. Green, Solar Energy Materials and Solar Cells, 2007, 91, 829-842.

22 A. Ishii and M. Hasegawa, Scientific Reports, 2017, 7, 41446.

23 F. Y. Wang, Y. H. Zhang, M. F. Yang, L. L. Yang, Y. R. Sui, J. H. Yang, Y. Zhao and X. D. Zhang, Advanced Functional Materials, 2018, 28, 1805001.

24 H. Kataoka, S. Omagari, T. Nakanishi and Y. Hasegawa, Optical Materials, 2015, 42, 411-416.

25 U. Resch-Genger, M. Grabolle, S. Cavaliere-Jaricot, R. Nitschke and T. Nann, Nature Methods, 2008, 5, 763-775.

26 K. D. Wegner and N. Hildebrandt, Chemical Society Reviews, 2015, 44, 4792-4834.

27 A. L. Efros, M. Rosen, M. Kuno, M. Nirmal, D. J. Norris and M. Bawendi, Physical Review B, 1996, 54, 4843-4856.

28 H. B. Bu, H. Yokota, K. Shimura, K. Takahasi, T. Taniguchi and D. Kim, Chemistry Letters, 2015, 44, 200-202.

29 H. Nishimura, Y. X. Lin, M. Hizume, T. Taniguchi, N. Shigekawa, T. Takagi, S. Sobue, S. Kawai, E. Okuno and D. Kim, AIP Advances, 2019, 9, 025223.

30 H. Nishimura, Y. X. Lin, M. Hizume, T. Taniguchi, N. Shigekawa, T. Takagi, S. Sobue, S. Kawai, E. Okuno and D. Kim, Chemistry Letters, 2019, 48, 1081-1083.

31 D. J. Norris, A. L. Efros and S. C. Erwin, Science, 2008, 319, 1776-1779.

32 S. C. Erwin, L. J. Zu, M. I. Haftel, A. L. Efros, T. A. Kennedy and D. J. Norris, Nature, 2005, 436, 91-94.

33 L. R. Bradshaw, K. E. Knowles, S. McDowall and D. R. Gamelin, Nano Letters, 2015, 15, 1315-1323.

34 C. L. Gan, Y. P. Zhang, D. Battaglia, X. G. Peng and M. Xiao, Applied Physics Letters, 2008, 92, 241111.

35 X. L. Yang, C. D. Pu, H. Y. Qin, S. J. Liu, Z. A. Xu and X. G. Peng Journal of the American Chemical Society, 2019, 141, 22882298.

36 C. L. Li and N. Murase, Langmuir, 2004, 20, 1-4.

37 H. B. Bu, T. Watanabe, M. Hizume, T. Takagi, S. Sobue, S. Kawai, E. Okuno and D. Kim, Materials Research Express, 2015, 2,036202.

38 S. Jun, J. Lee and E. Jang, ACS Nano, 2013, 7, 1472-1477.

39 Y. Liu, D. D. Yu, W. Zhu, X. Bai, Q. H. Shen, X. Y. Liu and J. G. Zhou, Chemical Research in Chinese Universities, 2017, 33, 327-332.

40 X. Michalet, F. F. Pinaud, L. A. Bentolila, J. M. Tsay, S. Doose, J. J. Li, G. Sundaresan, A. M. Wu, S. S. Gambhir and S. Weiss, Science, 2005, 307, 538-544.

41 P. Reiss, J. Bleuse and A. Pron, Nano Letters, 2002, 2, 781-784.

42 J. Selyaraj, A. Mahesh, V. Asokan, V. Baskaralingam, A. Dhayalan and T. Paramasivam, ACS Applied Nano Materials, 2018, 1, 371-383.

43 A. Aboulaich, M. Geszke, L. Balan, J. Ghanbaja, G. Medjahdi and R. Schneider, Inorganic Chemistry, 2010, 49, 10940-10948.

44 M. Hardzei and M. Artemyev, Journal of Luminescence, 2012, $132,425-428$.

45 Y. S. Lee, K. Nakano, H. B. Bu and D. G. Kim, Applied Physics Express, 2017, 10, 065001.
46 Y. S. Lee, H. B. Bu, T. Taniguchi, T. Takagi, S. Sobue, H. Yamada, T. Iwaki and D. Kim, Chemistry Letters, 2016, 45, 878-880.

47 L. H. Jing, S. V. Kershaw, Y. L. Li, X. Huang, Y. Y. Li, A. L. Rogach and M. Y. Gao, Chemical Reviews, 2016, 116, 10623-10730.

48 G. M. Dalpian and J. R. Chelikowsky, Physical Review Letters, 2006, 96, 226802.

49 P. Wu and X. P. Yan, Chemical Society Reviews, 2013, 42, 54895521.

50 V. Wood, J. E. Halpert, M. J. Panzer, M. G. Bawendi and V. Bulovic, Nano Letters, 2009, 9, 2367-2371.

51 R. Thakar, Y. C. Chen and P. T. Snee, Nano Letters, 2007, 7, 3429-3432.

52 B. T. Luong, E. Hyeong, S. Ji and N. Kim, RSC Advances, 2012 2, 12132-12135.

53 C. D. Pu, J. L. Ma, H. Y. Qin, M. Yan, T. Fu, Y. Niu, X. L. Yang, Y. F. Huang, F. Zhao and X. G. Peng, ACS Central Science, 2016, 2, 32-39.

54 G. C. Glaeser and U. Rau, Thin Solid Films, 2007, 515, 59645967.

55 E. Klampaftis, D. Ross, K. R. McIntosh and B. S. Richards, Solar Energy Materials and Solar Cells, 2009, 93, 1182-1194. 


\title{
Figures
}

Water-soluble ZnSe/ZnS:Mn/ZnS quantum dots convert UV to visible light for improved Si solar cell efficiency

\author{
Hisaaki Nishimuraa, Takaya Maekawa ${ }^{a}$, Kazushi Enomotob ${ }^{\text {, Naoteru Shigekawa }}{ }^{a}$, Tomomi \\ Takagic, Susumu Sobue ${ }^{c}$, Shoichi Kawaic, and DaeGwi Kim*a \\ ${ }^{a}$ Department of Applied Physics, Osaka City University, Osaka 558-8585, Japan \\ b. RIKEN Center for Emergent Matter Science (CEMS), Saitama 351-0198, Japan \\ 'Advanced Research and Innovation Center, DENSO CORPORATION, 500-1 Minamiyama, Komenoki- \\ cho, Nisshin, Aichi 470-0111, Japan
}




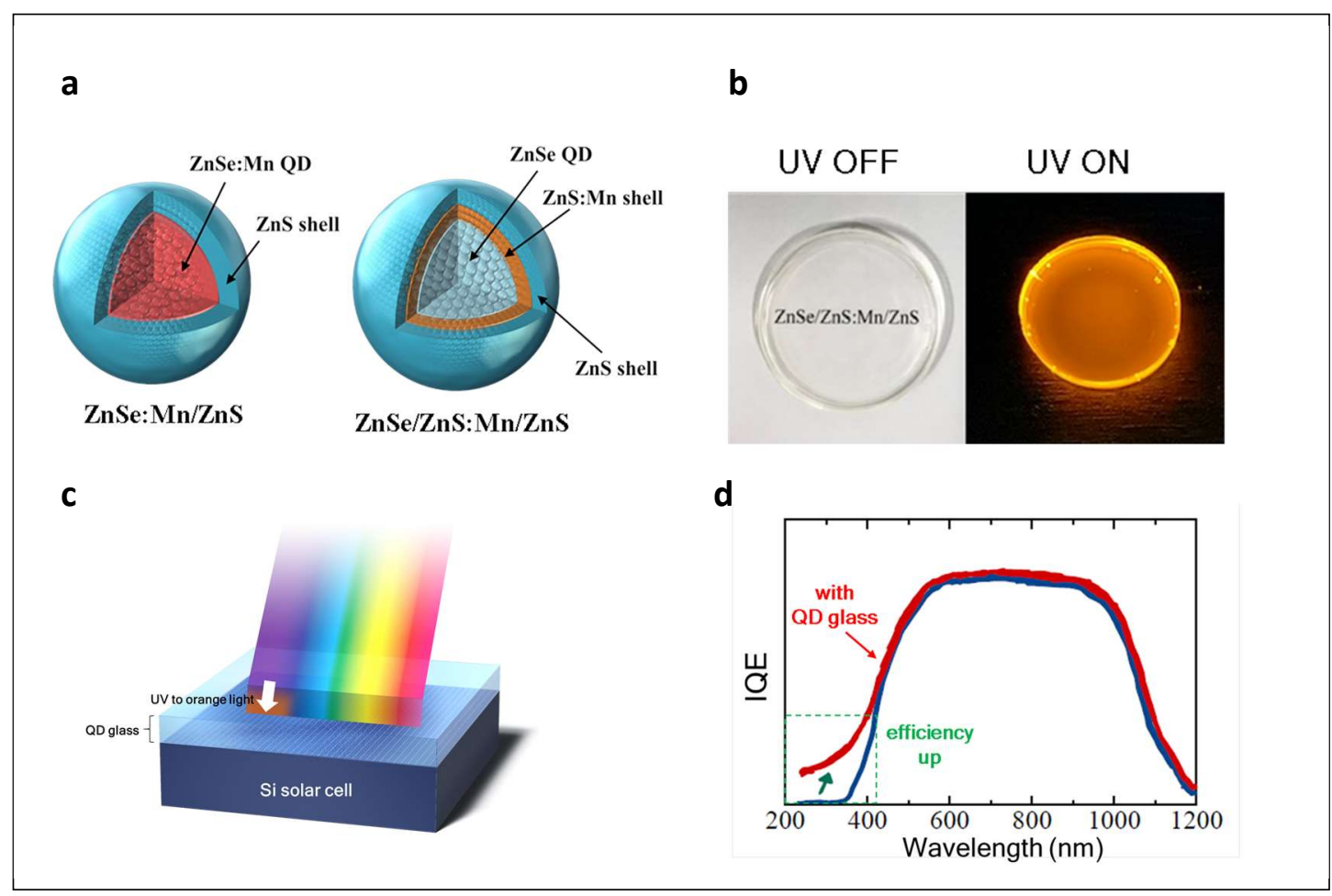

Figure 1. Concept of the present study. (a) Schematic of ZnSe:Mn/ZnS core/shell QDs and ZnSe/ZnS:Mn/ZnS core/shell/shell QDs. (b) Photographs of the QD wavelengthconversion glass under a room light and UV irradiation. The glass is transparent under room light and emits orange light under UV. (c) Schematic configuration of a solar cell combined with the QD wavelength-conversion glass. Visible light passes through the QD glass, while UV light is converted into orange light that reaches the solar cell. (d) Demonstration of how UV light can be used to improve the power generation. 


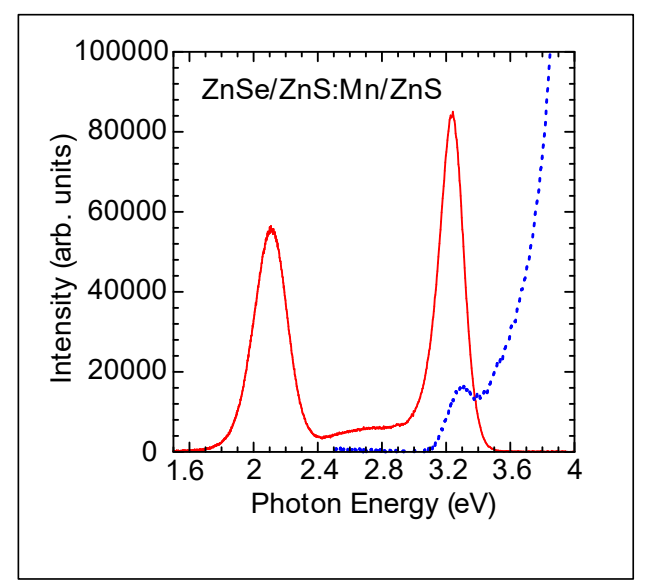

Figure 2. Absorption (blue dashed line) and PL (red solid line) spectra of the ZnSe/ZnS:Mn/ZnS core/shell/shell QDs. 
a

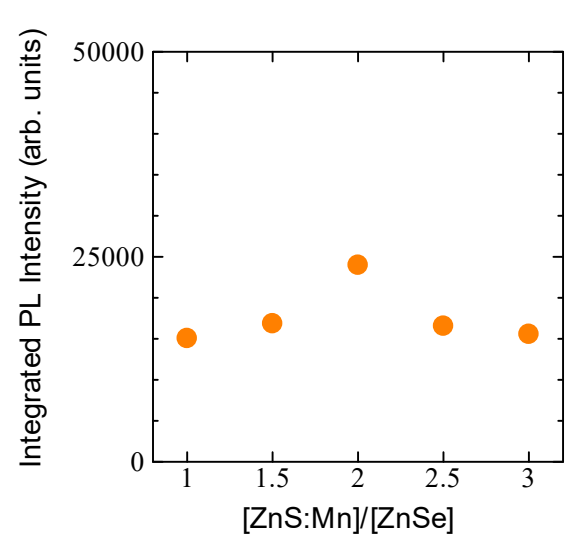

C

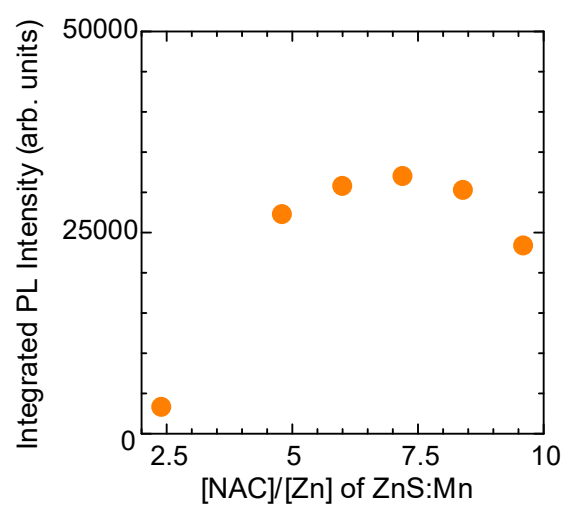

b

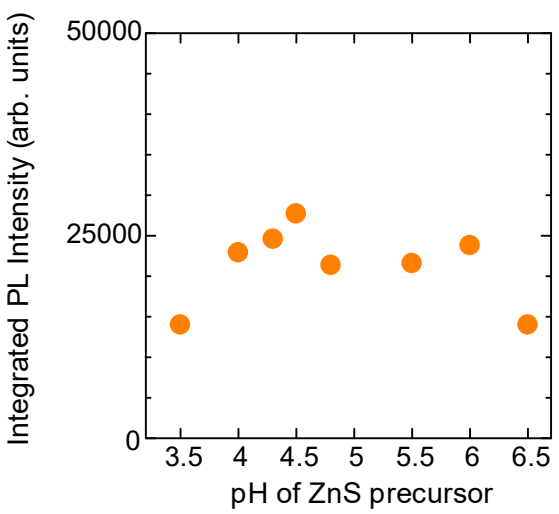

d

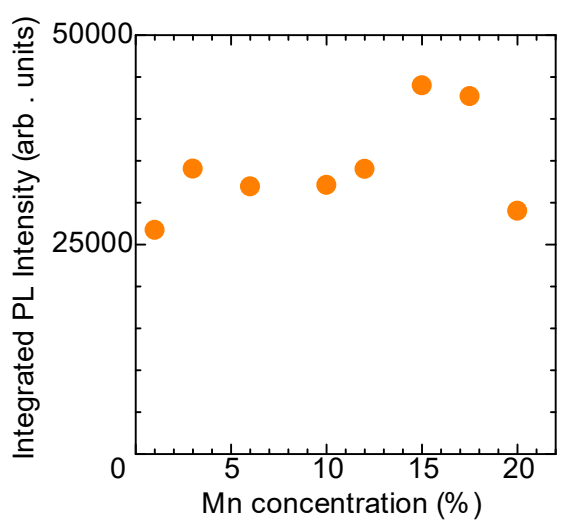

Figure 3. Integrated Mn PL intensity of ZnSe/ZnS:Mn/ZnS core/shell/shell QDs. Dependence of $\mathrm{Mn} \mathrm{PL}$ intensity on the (a) [ZnS:Mn]/[ZnSe] ratio, (b) pH of the $\mathrm{ZnS}$ precursor, (c) $[\mathrm{NAC}] /[\mathrm{Zn}]$ molar ratio of the $\mathrm{ZnS}: \mathrm{Mn}$ precursor, and (d) Mn concentration of the $\mathrm{ZnS}: \mathrm{Mn}$ precursor. 


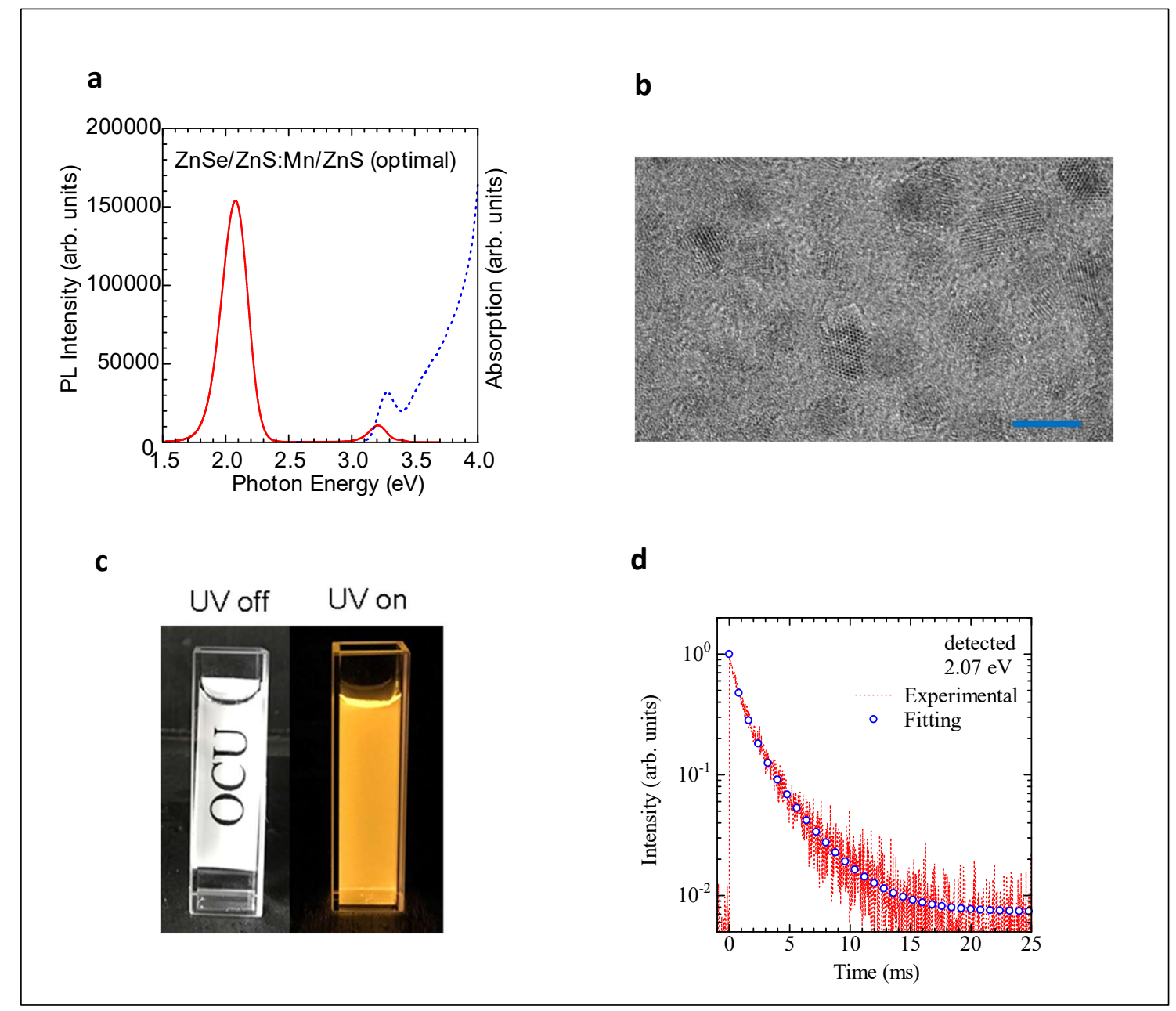

Figure 4. Properties of the ZnSe/ZnS:Mn/ZnS core/shell/shell QDs. (a) Absorption (blue dashed line) and PL (red solid line) spectra of the ZnSe/ZnS:Mn/ZnS core/shell/shell QDs. (b) TEM image of the ZnSe/ZnS:Mn/ZnS core/shell/shell QDs. The scale bar is 5 nm. (c) ZnSe/ZnS:Mn/ZnS core/shell/shell QD solution under a room light and UV irradiation. (d) PL decay profile of the ZnSe/ZnS:Mn/ZnS core/shell/shell QDs. 
a

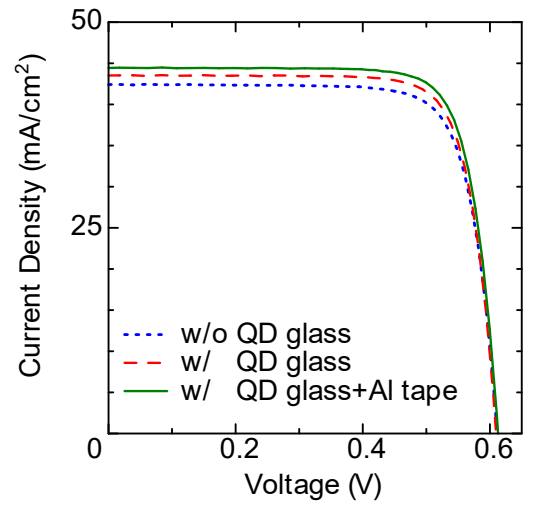

b

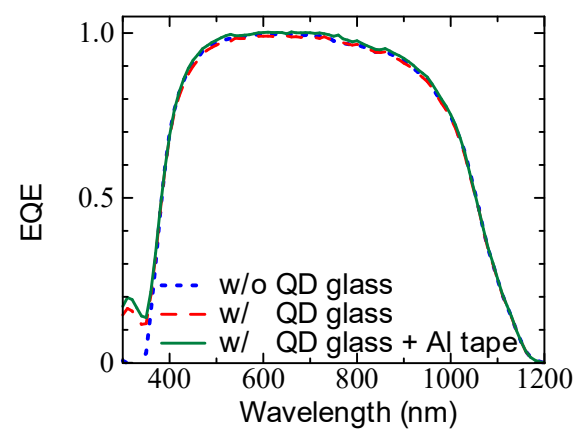

Figure 5. I-V characteristics and EQE of Si solar cells with and without the QD glass. (a) I-V curves under AM1.5G/1 SUN irradiation and (b) EQE spectra of Si solar cells without the QD glass (blue dotted lines), with the QD glass (red dashed lines), and with the QD glass and Al tape (green solid lines). The irradiation light intensity in the $I-V$ measurement is $100 \mathrm{~mW} / \mathrm{cm}^{2}$, and the irradiation light intensity in the EQE measurement is 1.0 $\mathrm{mW} / \mathrm{cm}^{2}$. 


\title{
Supporting Information
}

Water-soluble ZnSe/ZnS:Mn/ZnS quantum dots convert UV to visible light for improved Si solar cell efficiency

\author{
Hisaaki Nishimura ${ }^{a}$, Takaya Maekawa ${ }^{a}$, Kazushi Enomoto ${ }^{\text {, Naoteru Shigekawa }}{ }^{a}$, Tomomi \\ Takagic, Susumu Sobuec, Shoichi Kawaic, and DaeGwi Kim*a \\ a Department of Applied Physics, Osaka City University, Osaka 558-8585, Japan \\ b.RIKEN Center for Emergent Matter Science (CEMS), Saitama 351-0198, Japan \\ 'Advanced Research and Innovation Center, DENSO CORPORATION, 500-1 Minamiyama, Komenoki- \\ cho, Nisshin, Aichi 470-0111, Japan
}




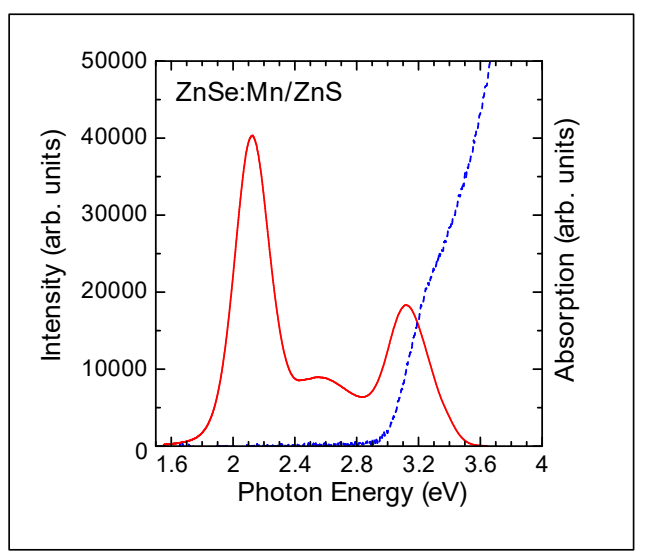

Figure S1. Optical properties of ZnSe:Mn/ZnS core/shell QDs. Absorption (dashed line) and PL spectra (solid line) of ZnSe:Mn/ZnS core/shell QDs. 


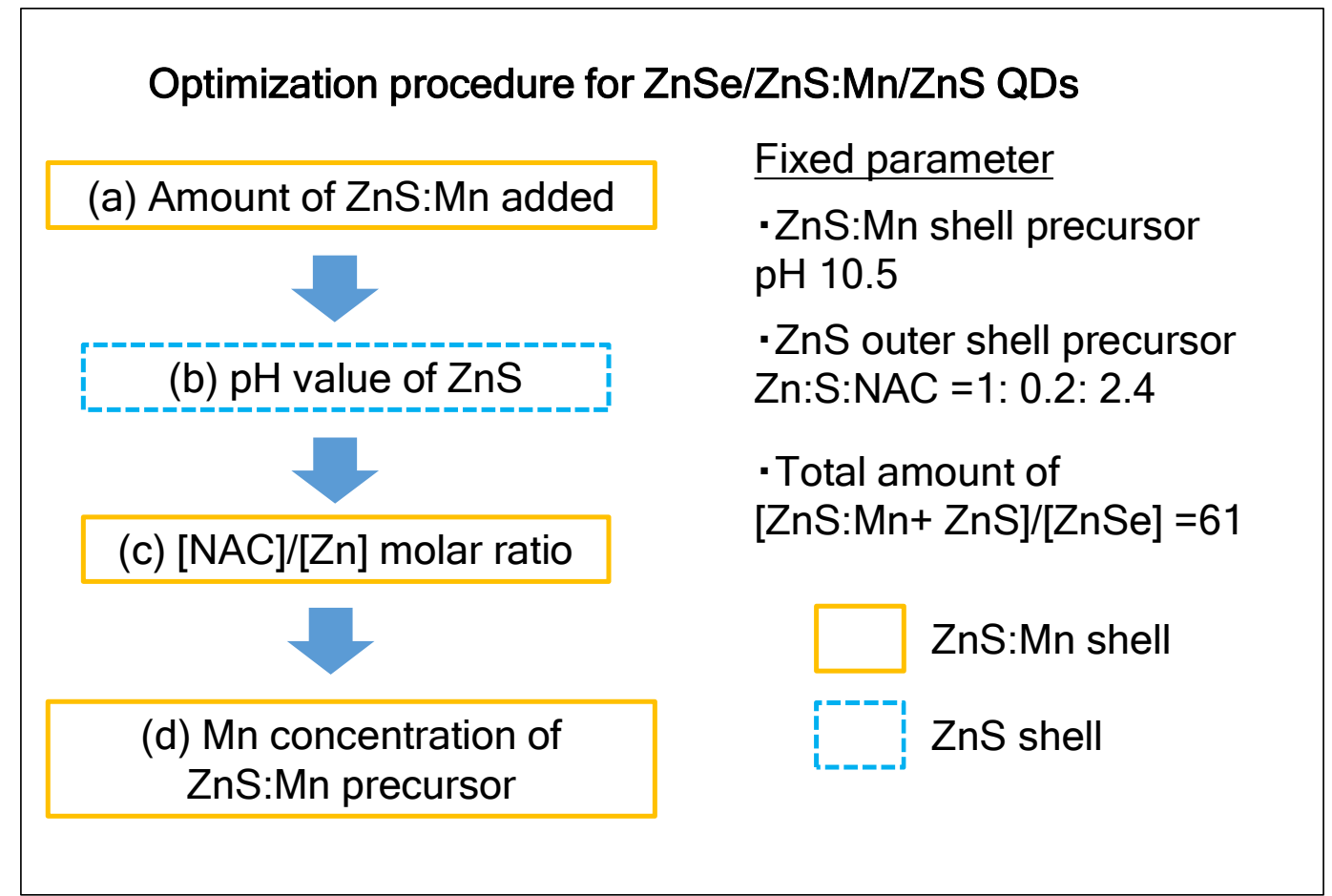

Figure S2. Flowchart for optimising the synthesis of ZnSe/ZnS:Mn/ZnS core/shell/shell QDs. 
a

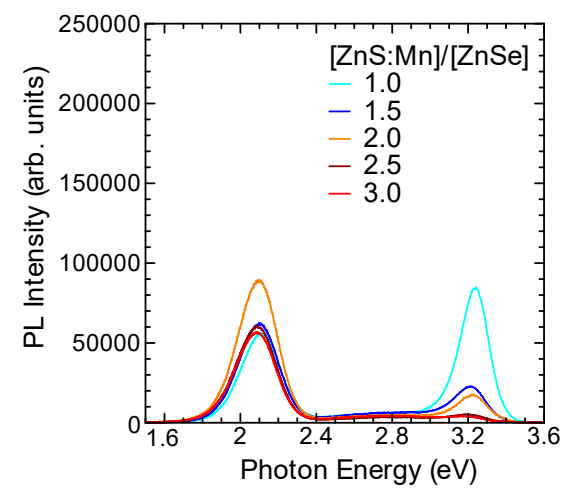

C

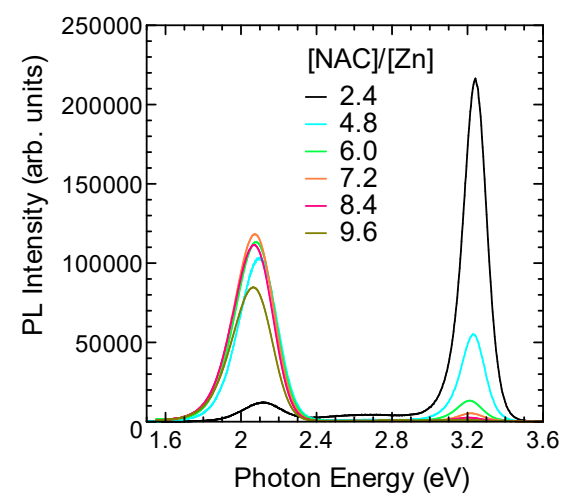

b

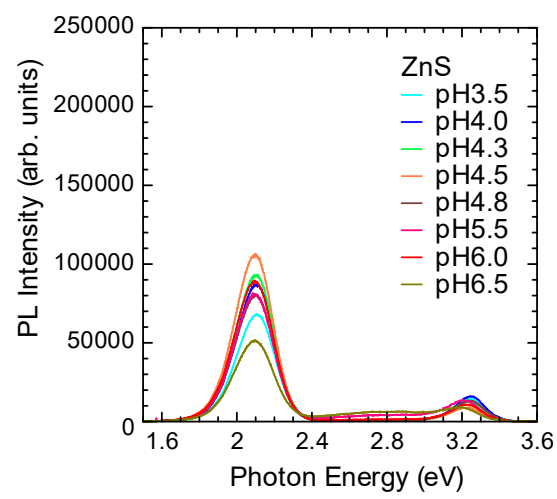

d

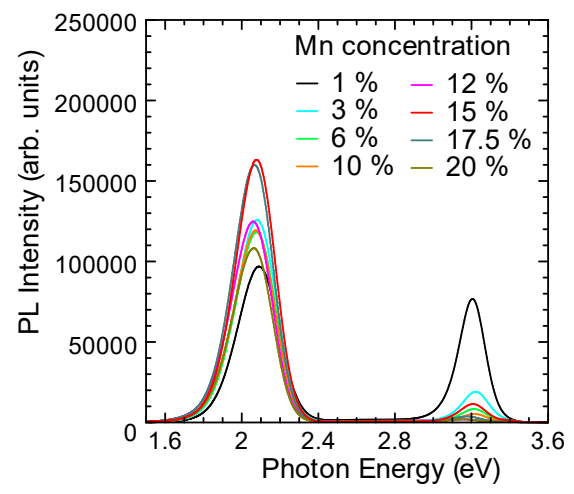

Figure S3. PL spectra of ZnSe/ZnS:Mn/ZnS core/shell/shell QDs prepared under various conditions. (a) Dependence on the [ZnS:Mn]/[ZnSe] ratio. (b) Dependence on the $\mathrm{pH}$ of the $\mathrm{ZnS}$ precursor. (c) Dependence on the $[\mathrm{NAC}] /[\mathrm{Zn}]$ molar ratio of the $\mathrm{ZnS}$ precursor. (d) Dependence on the Mn concentration of the ZnS:Mn precursor. 
a

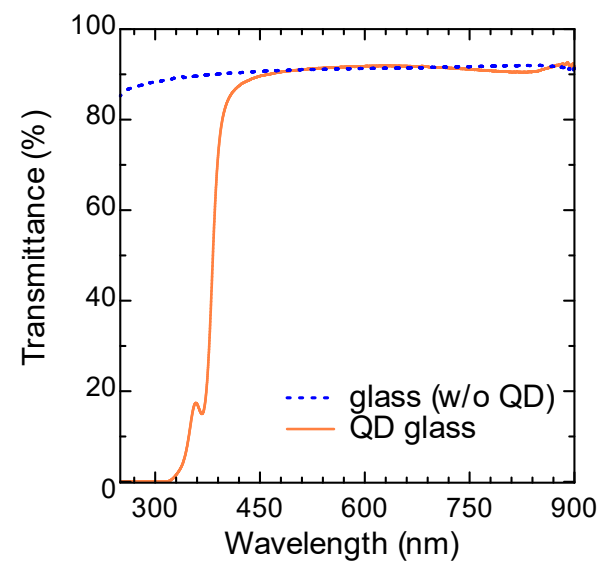

b

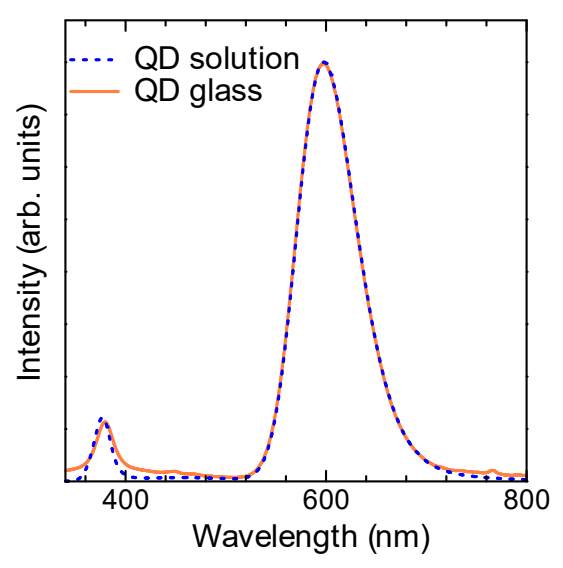

Figure S4. Optical wavelength-conversion glass (QD glass) measurements. (a) Transmittance spectra of sol-gel glass without the ZnSe/ZnS:Mn/ZnS core/shell/shell QD solution (dotted line) and with the QD solution (solid line). (b) PL spectra of the ZnSe/ZnS:Mn/ZnS core/shell/shell QD solution (dotted line) and the QD glass (solid line) (excited at $325 \mathrm{~nm}$ ). 


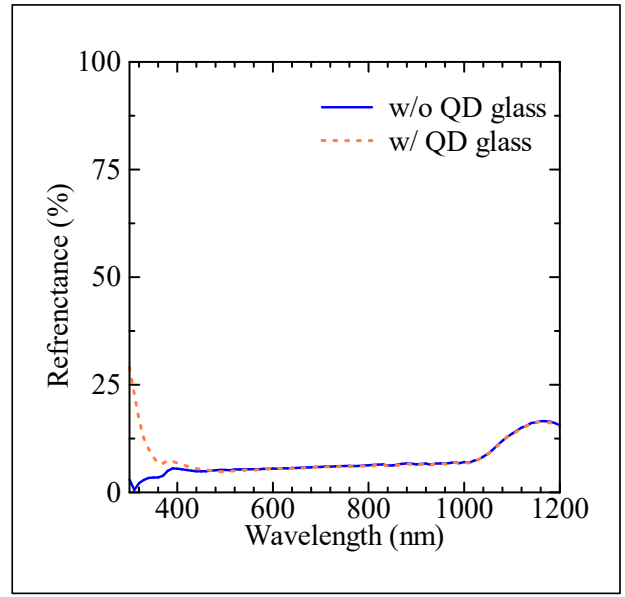

Figure S5. Surface reflectance of Si solar cells with and without the QD glass. 


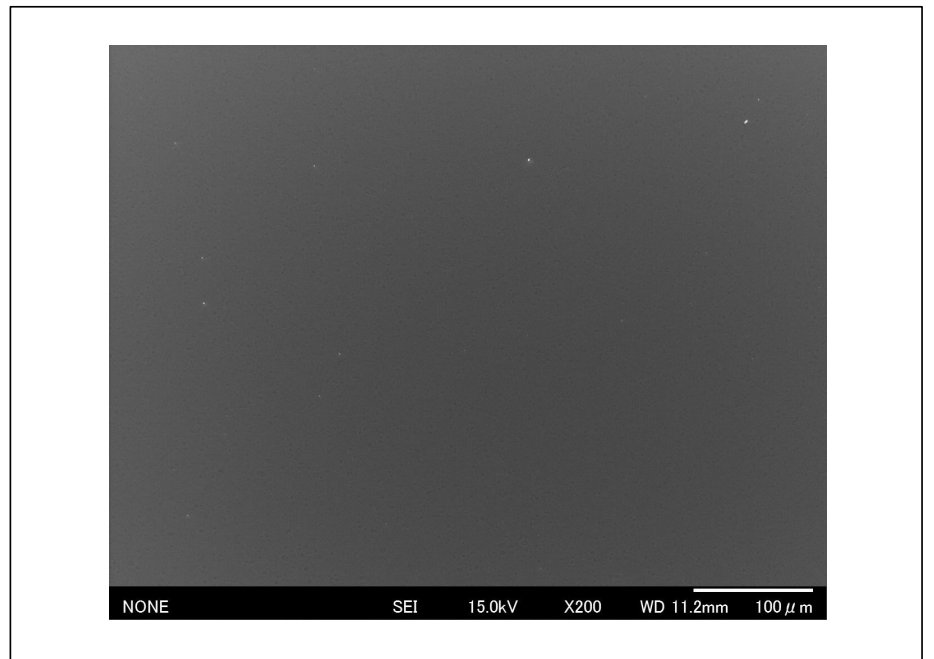

Figure S6. SEM image of the solar cell with the QD glass. 